\title{
Narrativas em cena e os processos de criação de João Brites em adaptações de romances para os palcos do Teatro $O$ Bando
}

\author{
JUAREZ GUIMARÃES DIAS
}

In this essay, we highlight some aspects of the processes and procedures of scenic creation by João Brites and Teatro $O$ Bando in adapting literary novels for the stage, examining his particular interest in working with novels and other literary forms not originally written for the stage: Gente Feliz com Lágrimas by João de Melo in 2002, Ensaio sobre a Cegueira by José Saramago in 2004 and Jerusalém by Gonçalo M. Tavares in 2008. This research was carried out during a six-month stay in Lisbon for literary, documental and field research with João Brites and his collective, identifying the stages of the processes and procedures used for the creation of those performances. The final analysis of empirical objects came from reading and studying the novels, comparing them to the dramaturgy and, consequently, to video recordings: an incursion into the field of performance genetics, which provides a methodological support for this research.

NOVELS ON STAGE / WORK IN PROGRESS / LITERARY ADAPTATION / JOÃO BRITES / TEATRO O BANDO

Este trabalho versa sobre parte da minha pesquisa de doutorado, que investiga um teatro de caráter narrativo e performativo que toma como matéria cênico-dramatúrgica obras a priori destinadas à leitura individual e silenciosa, transportando-as para a linguagem verbal, sonora e visual do teatro, em que o ator é o eixo principal da comunicação dessa textualidade com o espectador. Neste ensaio-dossiê, destacaremos aspectos dos processos e procedimentos de criação cênica de João Brites junto ao Teatro $\mathrm{O}$ Bando na adaptação de romances literários para os palcos, realçando seu gosto particular, e também do grupo, pela narrativa e pelo trabalho com textos não escritos originalmente para o palco: Gente Feliz com Lágrimas, de João de Melo, em 2002, Ensaio sobre a Cegueira, de José Saramago, em 2004, e Jerusalém, de Gonçalo M. Tavares, em 2008. ${ }^{1} \mathrm{~A}$ análise dos objetos empíricos partiu da leitura e do

1 Na altura da pesquisa, somavam-se quatro criações neste campo, das quais apenas uma não entrou no corpus de análise: o espetáculo Salário de Poetas (do romance do brasileiro Ricardo Guilherme Dick) foi realizado em parceira com a Cia. D'Artes do Brasil, em 2005, em que cada grupo montou sua versão e seus encenadores uma parceria colaborativa, o que merece um estudo particular. 
estudo dos romances, contrapondo-os à dramaturgia e, em consequência, aos registos em vídeo, uma incursão no campo da genética teatral, que oferece suporte metodológico à investigação.

UMA PESQUISA IN PROGRESS, UMA METODOLOGIA GENÉTICA

A genética de espetáculos, cujo pioneirismo é atribuído ao trabalho de Jean-Marie Thomasseau em fins da década de 1990 em França, e também Gay McAuley na Austrália, refere-se à reconstituição e análise de algumas etapas do percurso que atores, dramaturgos, encenadores e artistas da cena trilharam na confecção de seus trabalhos. O work in progress tem caracterizado muitas práticas cênicas contemporâneas e suscitado enorme interesse da genética teatral, com o objetivo de esclarecer a trajetória de criação artística, capitaneada por encenadores. Para Josette Féral, o campo atual dos estudos teatrais «opera dentro do centro nervoso onde a performance está em processo de construção, escolhendo retroceder no tempo para descobrir como o artista chegou a suas escolhas e de como a estética foi se construindo» (Féral, 2008: 229). Assim, nosso intuito é refazer os caminhos trilhados pelo encenador português em seus processos de criação dos espetáculos selecionados para o corpus analítico.

Para a inclusão de João Brites e do Teatro O Bando na pesquisa, foi fundamental o estágio de doutoramento no Centro de Estudos de Teatro da Universidade de Lisboa durante seis meses, a partir do Programa de Acordo de Cooperação Internacional CAPES-FCT (Unirio, Universidade de Lisboa e Universidade de São Paulo). O plano de estudos, com orientação local da professora Maria João Brilhante, proporcionou um mapeamento e conhecimento das artes cênicas e performativas contemporâneas de Portugal e também da Europa; possibilitou também contato e aproximação com o grupo, no qual puderam ser percebidos aspectos dos procedimentos de trabalho e, especificamente, de direção de atores, dramaturgia e encenação.

Foi feito um levantamento e pesquisa bibliográfica complementar em várias bibliotecas portuguesas, além de pesquisa documental sobre o Teatro $\mathrm{O}$ Bando, que se complementou no acervo do grupo. O profícuo e extenso material, ao mesmo tempo em que oferecia um rico acervo de pesquisa, apontou também um exaustivo exercício de concentração nos aspectos mais relevantes para esta investida intelectual. A convite de João Brites, realizei com ele um estágio-docência 
e artístico no curso de licenciatura em Teatro da Escola Superior de Teatro e Cinema (ESTC), que me permitiu aprofundar o conhecimento sobre seu pensamento artístico e verificar em ação seus procedimentos de direção de atores, de encenação e dramaturgia, que se aplicam ao trabalho no Teatro $\mathrm{O}$ Bando. A última etapa consistiu em entrevistas com João Brites e os atores/diretores Sara de Castro e Miguel Jesus.

Ter vivido em Lisboa não apenas proporcionou a aproximação com uma de nossas matrizes culturais e tantos encontros, trocas e interlocuções, mas principalmente o contato mais estreito com João Brites e o Teatro O Bando. Ao estar com eles, nos almoços de convívio ou nos ensaios abertos na sede do grupo, o espírito de comunidade contagia os participantes, que têm a oportunidade de conversar sobre os trabalhos, celebrar o encontro com a arte e seus princípios humanistas e sociais.

JOÃO BRITES E SEUS PROCESSOS DE CRIAC̣ÃO:

A CENA COMO ESCRITA E PINTURA TRIDIMENSIONAL

«Antes, sobretudo como cenógrafo, eram as mãos que faziam, e descobriam fazendo, o conteúdo que me predispunha a partilhar. Agora tudo se passa muito mais na mente, mas o que imagino continua a ser elaborado, fazendo e desfazendo, como se fossem as mãos que continuassem a trabalhar» (2011b), assim, João Brites define sua prática como dramaturgo e encenador. Artista plástico de formação, estudou pintura e gravura na École Nationale Supérieure des Arts Visuels - La Cambre, em Bruxelas, onde viveu o exílio político da ditadura salazarista durante oito anos, de 1966 a 1974. Nesse período, com outros artistas e amigos, experienciou um modo de vida em comunidade, contagiada especialmente pelas manifestações de maio de 1968 em França, que desencadeou uma greve geral de estudantes e trabalhadores, alcançando proporções revolucionárias.

Ao retornar a Portugal com o fim do período de degredo, João Brites fundou de forma independente o Teatro de Animação O Bando ao lado de outros companheiros. Artistas desconhecidos em seu país, estavam muito influenciados pelo teatro de rua de Bruxelas pelo teatro operário de Paris e pelo teatro universitário de Lisboa. Destacam-se as formulações marxistas que originaram os princípios do grupo e a sua capacidade de interferir e propor mudanças na situação política do país: a militância percebeu no 25 de Abril uma «situação histórica relativamente 
favorável», cujos propósitos panfletários encontraram na animação voltada para crianças e na itinerância uma «aproximação do público pelas margens» (Serôdio, 1994: 142).

Primando ética e artisticamente pelo estar em grupo, O Bando tem em sua gênese o fazer teatral como prática de uma coletividade que deve se sobrepor a qualquer individualismo. No caso d'O Bando, a preservação de um núcleo estável de participantes garante a conservação (e consequentemente a perpetuação) do pensamento e da prática do grupo e em grupo. Entretanto, nos primeiros espetáculos a construção partia de improvisações e de uma dramaturgia e encenação coletivas, mas rapidamente o grupo demandou por uma liderança. João Brites tornou-se seu principal dramaturgo e encenador, lugar que também é ocupado eventualmente por outros artistas. A constituição dessa autoridade não alterou a base ideológica e artística d'O Bando, visto que, como esclareceu Brites, o processo do grupo continua a ser coletivo, ainda que liderado por ele.

Reivindicando o retorno da arte como parte integrante da vida, abandonando uma postura formal e decorativa, João Brites e o Teatro O Bando sabem que nas origens do teatro está uma necessidade de comunicação, entendida como processo em dupla direção, e a possibilidade de poderem viver situações por meio do lúdico, procurando responder às questões que cada época lhes permite. A eles interessa, sobretudo, atender às funções que consideram originárias do teatro ligadas à vida, ao trabalho, à ritualização e à exteriorização dos sentimentos do ser humano. Portanto, de uma proposta inicial de textualidade coletiva, o grupo encaminha-se para uma elaboração dramatúrgica mais complexa, que envolve a escrita a partir de contos, crônicas, documentos históricos, romances e poemas. A transição para textos exteriores ao grupo faz emergir a figura de João Brites como dramaturgo-encenador, funções que passam a caminhar, para ele, a par e passo.

«Criar é escolher entre uma infinidade de hipóteses», afirma João Brites inúmeras vezes em textos e também nas suas aulas na ESTC. Seu processo criativo tem início com a escolha do texto, que sempre passa pela aprovação do grupo ou, mais recentemente, da direção artística. Sara de Castro ressalta a capacidade do encenador de lançar ideias e linhas de ação para os espetáculos, indicando os constrangimentos que são postos desde o princípio, mas deixando alargada a abertura para outras tantas hipóteses, que podem surgir do elenco ou de outros integrantes da equipe. Ele corrobora: 
Quer dizer que é perfeitamente admissível que, nos primeiros ensaios ou nas primeiras reuniões, existam contributos que pareçam não ter sentido nenhum. À partida, não se trata de construir uma lógica demasiado coerente e em total sintonia com os princípios dramatúrgicos estabelecidos. O contraste insólito, a inesperada complementaridade e até a aparente aberração disparatada podem aumentar o número de hipóteses e ser determinantes para um mais multifacetado esclarecimento dramatúrgico. (Brites, 2011b)

Os processos criativos têm início com os estágios, sistema laboratorial que o grupo vem perseguindo ao longo dos tempos e que atua como uma preparação para os ensaios propriamente ditos. Normalmente, a direção artística e o elenco isolam-se fora da sede de trabalho em períodos que variam de dias a semanas, conforme disponibilidade e/ou necessidade. Algumas vezes os estágios ocorrem até um ano antes de a montagem se concretizar, como no caso de Ensaio sobre a Cegueira. Todos os integrantes envolvem-se em conversas, discussões a respeito do assunto tratado pelo texto escolhido, realizam workshops, experimentações, construindo coletivamente uma partilha do universo a ser encenado. Às diretrizes pré-formuladas que orientam o encenador (seu projeto de encenação, que ele denomina «mapa de desenvolvimento») vão se somando contribuições de todos os artistas, pondo em causa algumas proposições, reafirmando outras e agregando novas. Os estágios parecem funcionar como uma espécie de incubadora de criação, em que ideias, conceitos e perspectivas têm a oportunidade de ser testadas, discutidas e amadurecidas. A primeira versão da dramaturgia é escrita pelo encenador na tentativa de materializar e visualizar o conceito e a proposta da montagem, mas que será rescrita ao longo do processo, principalmente no encontro com o elenco. Para João Brites, o tempo disponível para os estágios é fundamental para:

deixar assentar pressupostos e sugestões para que naturalmente venha ao de cima o que não ficou esquecido. A leitura actualizada do que parece essencial baseia-se numa seleção das coisas que queremos repetir e queremos ver esclarecidas sem sermos capazes de compreender totalmente. Interessa-nos o que fica ainda interrogado e o que alimenta o enigma, ou os enigmas que iluminam os conteúdos sem os reduzirem. (Brites, 2011b) 
Seu primeiro procedimento dramatúrgico é o confronto do mapa de desenvolvimento com o texto original visando a construção de um apêndice textual. Em seguida, parte para outra seleção, dividindo o que será posto em discurso direto e o que ficará nas didascálias, em segundo plano, como sugestão de subtexto para a cena e os atores. O critério orientador dessa divisão é determinar o que pode ser mostrado pela cena e aquilo que pode ser dito pelas personagens, buscando não incorrer numa ilustração do texto falado. «Não vou dizer e demonstrar. Vou fazer uma seleção que abra no discurso verbal algo que o discurso visual não contém. Quando eu não resolvo o discurso visual, tenho tendência a estabelecer uma complementaridade no discurso verbal» (Brites, 2011b).

O processo estrutura-se a partir de um eixo que determina os conflitos principais e secundários e como se desenvolvem, verificando onde estão os momentos de articulação entre eles, quando muda a tensão, como se cria uma dinâmica narrativa e de que forma pode investir-se numa imprevisibilidade para o espectador. «Há a necessidade de uma estrutura de desenvolvimento, mas também há um jogo constante com o acaso e a intuição. Não me submeto totalmente às regras que estabeleço» (Brites, 2011b). A abertura e o compartilhamento das ideias, principalmente com os atores, é o diferencial desse modo de condução processual. Sara de Castro observa o status de criador que o ator tem no grupo:

Os atores aqui são criadores, absolutamente. Não no sentido de serem cocriadores $[\mathrm{sic}]$ e assinarem uma criação coletiva. A autoria é do João, isso é inequívoco. Mas começa-se muitas vezes os processos a perguntar aos atores «que sentido tem isto para vocês?» ou «como é que vocês se posicionam face ao que vamos fazer?». Portanto, o ator é sempre convocado a uma implicação pessoal, a uma contribuição, não só a um posicionamento em relação ao seu trajeto artístico, mas, sobretudo, a um compromisso com as suas próprias convicções pessoais, políticas, etc., amores, desamores, tudo. Tudo é matéria para o processo criativo e o João aproveita-se, entre aspas, dessas contribuições para a construção do espetáculo. (Castro, 2011)

A dramaturgia é a coluna vertebral da criação de João Brites, que não a dissocia da cenografia e da encenação. Trata-se de uma escrita aglutinadora, que elabora a proposta de criação de maneira artística, analítica e teórica, realizada por meio dos «textos de trabalho». Esses são a tradução em escrita da concepção geral do espetáculo, que determina 
ainda as opções estéticas, culturais e políticas e os modos de relação com o espectador. Este trabalho está ligado diretamente ao conceito de dramatografia, termo cunhado por João Brites para pensar numa escrita que envolve a concepção espacial e que remete à etimologia de cenografia (escrever a cena), o que «evidencia uma prática baseada na mão, no traço, num pensar pictórico, que conduz a mente ao espaço e à ocupação desses espaços, por conseguinte, ao gesto no interior desse espaço» (Teatro O Bando, 1980: 20). A dramaturgia, portanto, não se restringe ao texto falado das personagens nem às indicações para a encenação: é uma escrita que busca determinar os aspectos globais do espetáculo.

O texto de trabalho divide-se em quatro colunas: a primeira apresenta o texto a ser falado pelas personagens e os diálogos; a segunda inclui a descrição da ação, títulos das cenas/quadros, rubricas e partitura gestual; a terceira busca apontar os efeitos pretendidos na cena (música, luz, projeções) e a última a cronologia temporal do espetáculo. Esse material dramatúrgico permite dois tipos de leitura: por um lado, há a vertical, em que se pode perceber a sequência de cenas e acontecimentos, enquanto a horizontal oferece a perspetiva da simultaneidade, ou seja, indica qual o subtexto do ator/cena no momento em que se fala um determinado texto e quais os efeitos cênicos, como se pode observar abaixo numa reprodução da dramaturgia de Gente Feliz com Lágrimas (Brites, 2002: 4):

\section{TEXTO DE TRABALHO}

\begin{tabular}{|c|c|c|c|}
\hline 1 & 2 & 3 & 4 \\
\hline $\begin{array}{l}\text { RECORDAÇÕES DA } \\
\text { CASA........3 } \\
\text { NUNO } 90 \\
\text { A porta range sob o impulso } \\
\text { do joelho. O seu vidro fosco } \\
\text { tilinta nas calhas. (460) }\end{array}$ & $\begin{array}{l}\text { Desiste de procurar. Pousa as malas } \\
\text { e é como se chegasse a sua casa. } \\
\text { Imita os barulhos das coisas. Olha } \\
\text { para a porta que acaba de transpôr } \\
\text { [sic] e surpreende-se de a ver } \\
\text { aberta. }\end{array}$ & $\begin{array}{l}\text { LUM B 02: Solar } \\
\text { 02/19 } \\
\text { Voz Marta: bébé } \\
\text { Nuno: ar agudo } \\
\text { Motor Marta: pulsos } \\
\text { Nuno: coluna su }\end{array}$ & $\begin{array}{l}5: 00 \\
05: 02 \\
05: 04 \\
05: 06 \\
05: 08 \\
05: 10 \\
05: 12 \\
05: 14 \\
05: 16 \\
05: 18\end{array}$ \\
\hline
\end{tabular}




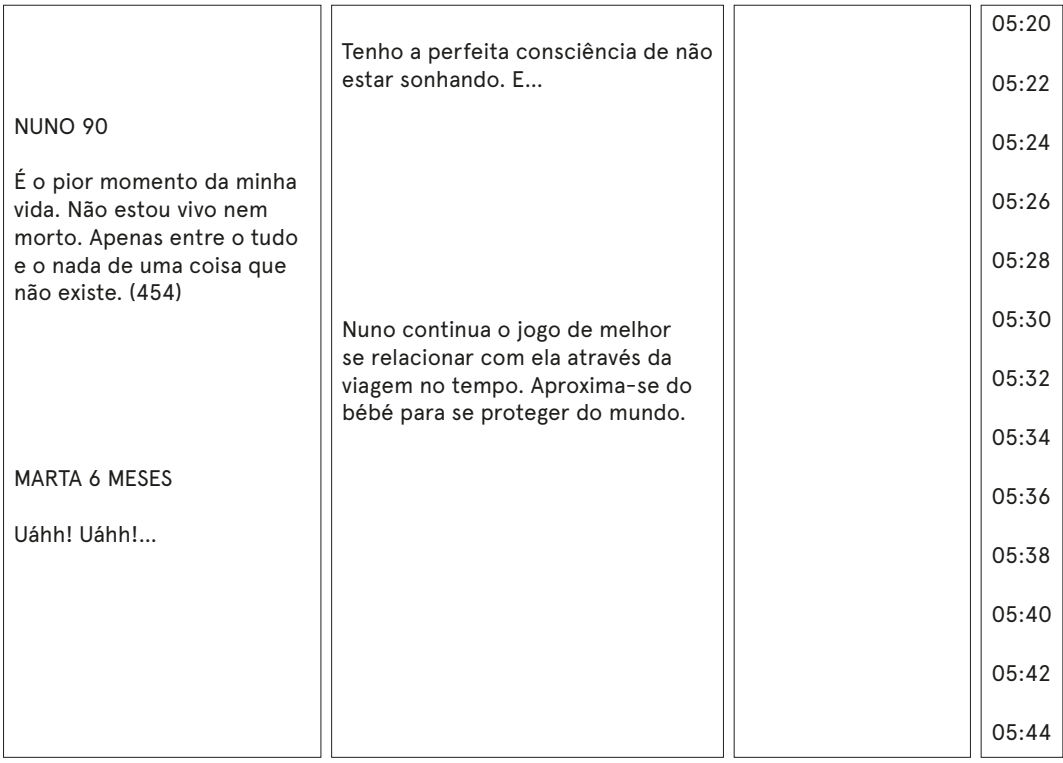

Examinando a primeira coluna (da esquerda para a direita), tem-se o título da cena «Recordações da casa», acompanhado na segunda por indicações da idade que as personagens têm: $\mathrm{N}$ [Nuno] (90) [anos] e M [Marta] oo-01 [do nascimento a 1 ano]. A composição mostra na terceira coluna referências à iluminação «solar» da cena. Os diálogos são acompanhados pela rubrica que anuncia a idade das personagens, «NUNO 90», «MARTA 3 MESES» e insere as páginas do romance em que foram extraídos os respectivos textos, «460», «454», o que já explicita o gesto dramatúrgico de cortar e colar, pois não obedece à sequência do original. Paralelamente, há as rubricas da encenação e orientações à interpretação: «Desiste de procurar. Pousa as malas e é como se chegasse a sua casa. Imita os barulhos das coisas. Olha para a porta que acaba de transpôr [sic] e surpreende-se de a ver aberta.» O dramaturgo-encenador incorpora nas rubricas fragmentos do romance, que na dramaturgia se convertem em subtexto para o ator, como se pode encontrar destacado por cor diferente no texto de trabalho: «Tenho a perfeita consciência de não estar sonhando. E...» 


\begin{tabular}{|c|c|c|}
\hline ROMANCE & TEXTO DE TRABALHO (COLUN & S 1 e 2) \\
\hline 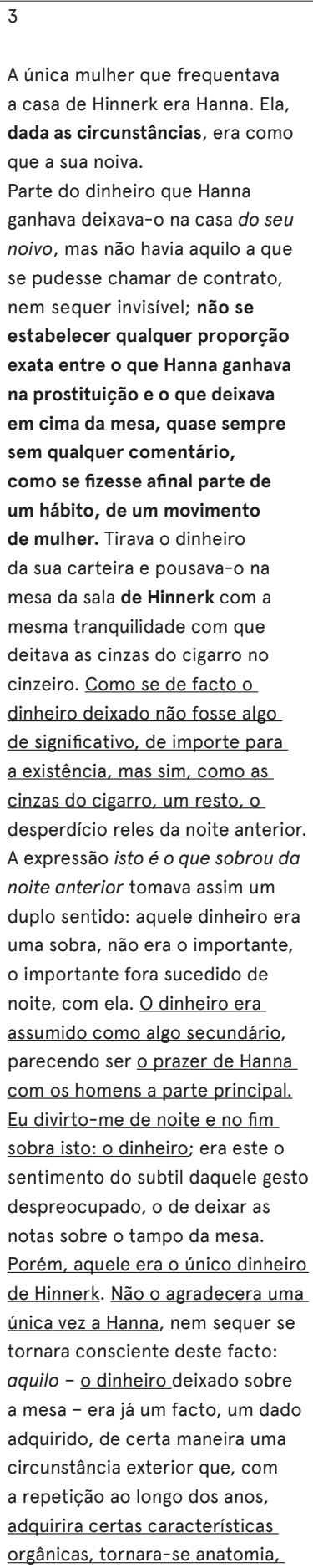 & $\begin{array}{l}\text { HANNA } 41 \text { FALA De facto o } \\
\text { dinheiro que te deixo não } \\
\text { é algo de significativo, de } \\
\text { importante para a existência, } \\
\text { mas sim, como as cinzas } \\
\text { do cigarro, um resto, o } \\
\text { desperdício reles da noite } \\
\text { anterior. (.) O dinheiro } \\
\text { é assumido como algo } \\
\text { secundário, }\end{array}$ & $\begin{array}{l}\text { A única mulher que frequentava } \\
\text { a casa de Hinnerk era Hanna. } \\
\text { Ela era como que a sua } \\
\text { noiva. Parte do dinheiro que } \\
\text { Hanna ganhava deixava-o } \\
\text { na casa do seu noivo, mas } \\
\text { não havia aquilo a que se } \\
\text { pudesse chamar de contrato, } \\
\text { nem sequer invisível. Tirava } \\
\text { o dinheiro da sua carteira e } \\
\text { pousava-o na mesa da sala } \\
\text { com a mesma tranquilidade } \\
\text { com que deitava as cinzas do } \\
\text { cigarro no cinzeiro. }\end{array}$ \\
\hline
\end{tabular}




\begin{tabular}{|c|c|c|}
\hline ROMANCE & TEXTO DE TRABALHO (COLUN & 1 e 2) \\
\hline $\begin{array}{l}\text { pertencia-lhe, tal como o seu } \\
\text { medo. Agarrava com a mão direita } \\
\text { o dinheiro, antes de sair para a } \\
\text { rua, amachucando-o como se } \\
\text { fosse papel, e colocava-o no bolso } \\
\text { das calças, mas era como se nada } \\
\text { sucedesse. Não tinha consciência } \\
\text { desse pequeno gesto, aquele } \\
\text { dinheiro não era apenas dele, } \\
\text { era ele. }\end{array}$ & $\begin{array}{l}\text { HINNERK } 31 \text { FALA É o teu } \\
\text { prazer com os homens a } \\
\text { parte principal... } \\
\text { HINNERK } 31 \text { EXPLICA } \\
\text { Divirte-se de noite e no fim } \\
\text { sobra isto: o dinheiro; } \\
\text { HANNA } 41 \text { FALA O único } \\
\text { dinheiro de Hinnerk. Não é? } \\
\text { HINNERK } 31 \text { FALA Não o } \\
\text { agradeci uma única vez, } \\
\text { HANNA } 41 \text { EXPLICA O dinheiro } \\
\text { (.) adquiriu características } \\
\text { orgânicas, tornou-se } \\
\text { anatomia, pertence-lhe, tal } \\
\text { como o seu medo. } \\
\text { (Brites, 2008: 13) }\end{array}$ & $\begin{array}{l}\text { Hinnerk agarrava com a } \\
\text { mão direita o dinheiro, } \\
\text { antes de sair para a rua, } \\
\text { amachucando-o como se } \\
\text { fosse papel, e colocava-o } \\
\text { no bolso das calças, mas era } \\
\text { como se nada } \\
\text { sucedesse. Não tinha } \\
\text { consciência deste gesto, } \\
\text { aquele dinheiro não era } \\
\text { apenas dele, era ele. } \\
\text { nem sequer eu próprio tomei } \\
\text { consciência deste facto: }\end{array}$ \\
\hline
\end{tabular}

A dramaturgia de João Brites realiza uma nova escrita a partir do texto original. Destaca-se um fragmento de Jerusalém (pp. 25-26) para demonstrar algumas operações dramatúrgicas, como a passagem do discurso indireto (narrador do romance) para o direto (personagem da dramaturgia): os trechos em negrito referem-se aos que foram suprimidos, enquanto os sublinhados são aqueles que passaram para o texto falado da personagem, restando os demais à rubrica (segunda coluna).

Com essa divisão e alguns rearranjos, o encenador-dramaturgo revela suas escolhas entre o que será falado pela personagem e aquilo que somente $o$ ator deve ter conhecimento para sua composição. Ele prefere dosar a utilização de textos narrativos-descritivos, dando mais espaço àqueles que servem melhor para a construção de diálogos, dramatúrgicos e cênicos, por sua enunciação direta. A voz do narrador, por sua vez, neste 
excerto é transferida para a personagem em algumas situações de explicação ou pensamento: «HANNA 41 EXPLICA O dinheiro adquiriu características orgânicas, tornou-se anatomia, pertence-lhe, tal como o seu medo.»

No Ensaio sobre a Cegueira, a profusão de diálogos e falas no romance de Saramago corroborou prontamente para sua transferência ao texto dramatúrgico. João Brites reconhece que, por isso, foi o texto mais fácil que já adaptou. Vejamos no quadro seguinte, em que foram destacados em negrito os textos utilizados em discurso direto, enquanto os sublinhados são os textos descartados que não foram aproveitados nas rubricas: Os procedimentos de edição e deslocamento são caros ao exercício de

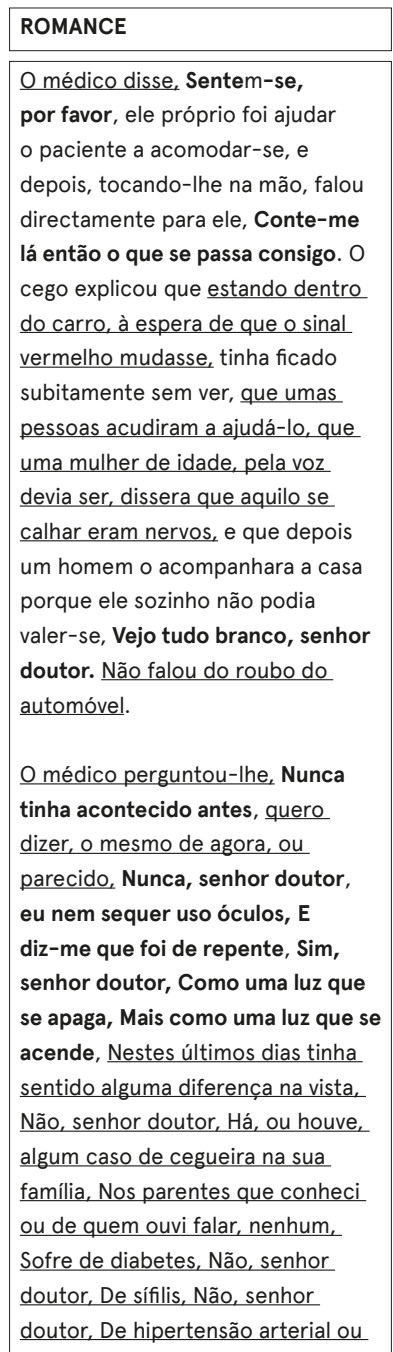

\section{TEXTO DE TRABALHO (COLUNAS 1 e 2)}

MÉDICO: Sente-se, por favor, Conte-me lá então o que se passa consigo.

CEGUINHO: Vejo tudo branco, senhor doutor.

MÉDICO: Nunca lhe tinha acontecido antes,

CEGUINHO: Nunca, senhor doutor, eu nem sequer uso óculos,

MÉDICO: E diz-me que foi de repente,

CEGUINHO: Sim, senhor doutor,

MÉDICO: Como uma luz que se apaga,

CEGUINHO: Mais como uma luz que se acende,

MÉDICO: Bom, vamos lá então observar esses olhos. Apoie aqui o queixo, mantenha os olhos abertos, não se mexa.
O Médico vai ajudar o paciente a acomodar-se. Tocando-Ihe na mão, falou directamente para ele.

O cego explica que ficou subitamente sem ver, e que um homem o acompanhou a casa porque ele sozinho não podia valer-se.
O cego abre-os muito, como para facilitar o exame 


\begin{tabular}{|c|c|c|}
\hline ROMANCE & TEXTO DE TRABALHO (COLUN & 1 e 2) \\
\hline $\begin{array}{l}\text { intracraniana, Da intracraniana não } \\
\text { sei, do mais sei que não sofro, lá } \\
\text { na empresa fazem-nos inspecções, } \\
\text { Deu alguma pancada violenta } \\
\text { na cabeça, hoje ou ontem, Não, } \\
\text { senhor doutor, Quantos anos tem, } \\
\text { Trinta e oito, Bom, vamos lá então } \\
\text { observar esses olhos. O cego } \\
\text { abriu-os muito, como para facilitar } \\
\text { o exame, mas o médico tomou-o } \\
\text { por um braço e foi instalá-lo por } \\
\text { trás de um aparelho que alguém } \\
\text { com imaginação poderia ver como } \\
\text { um novo modelo de confessionário, } \\
\text { em que os olhos tivessem } \\
\text { substituído as palavras, como o } \\
\text { confessor a olhar directamente } \\
\text { para dentro da alma do pecador, } \\
\text { Apoie aqui o queixo, recomendou, } \\
\text { mantenha os olhos abertos, não } \\
\text { se mexa. A mulher aproximou-se } \\
\text { do marido, pôs-lhe a mão no } \\
\text { ombro, disse, Verás como tudo } \\
\text { se irá resolver. O médico subiu e } \\
\text { baixou o sistema binocular do seu } \\
\text { lado, fez girar parafusos de passo } \\
\text { finíssimo, e principiou o exame. Não } \\
\text { encontrou nada na córnea, nada na } \\
\text { esclerótica, nada na íris, nada na } \\
\text { retina, nada no cristalino, nada na } \\
\text { mácula lútea, nada no nervo óptico, } \\
\text { nada em parte alguma. Afastou-se } \\
\text { do aparelho, esfregou os olhos, } \\
\text { depois recomeçou o exame desde } \\
\text { o princípio, sem falar, e quando } \\
\text { outra vez terminou tinha na cara } \\
\text { uma expressão perplexa, Não lhe } \\
\text { encontro qualquer lesão, os seus } \\
\text { olhos estão perfeitos. } \\
\text { (Saramago, 1995: } 27-8 \text { ) }\end{array}$ & $\begin{array}{l}\text { CEGUINHA: Verás como tudo } \\
\text { se irá resolver. } \\
\text { MÉDICO: Não lhe encontro } \\
\text { qualquer lesão, os seus olhos } \\
\text { estão perfeitos. }\end{array}$ & $\begin{array}{l}\text { Aproxima-se dele, pondo-lhe } \\
\text { a mão no ombro. O médico } \\
\text { sobe e baixa o sistema } \\
\text { binocular. Principia o exame. } \\
\text { Não encontra nada. Afasta-se } \\
\text { do aparelho, esfrega os olhos, } \\
\text { recomeça o exame desde o } \\
\text { princípio, sem falar, e quando } \\
\text { termina tem na cara uma } \\
\text { expressão perplexa. }\end{array}$ \\
\hline
\end{tabular}

escrita de João Brites e permitem promover uma profunda cirurgia no texto original, destacando e separando aquilo que lhe interessa. Os textos em discurso direto no romance se prestam diretamente à sua passagem para o texto do espetáculo, em que a escrita de José Saramago é preservada. Pela edição, o exercício da liberdade defendido pelo encenador-autor consente que ele promova saltos na ordem do romance, servindo-se do gesto de recortar e colar e por isso remontar o texto original. Trata-se de reunir na mesma cena trechos recolhidos em páginas e capítulos distintos (assinalados na primeira coluna entre parênteses, 
182/304/182/225), realizando elipses narrativas com vista a manter concentrado aquele conflito cênico, como em Gente Feliz com Lágrimas (Brites, 2002:16), cujo fragmento do texto de trabalho inclui ainda mapa da cenografia, apontando a posição em que as personagens devem estar naquele momento (o círculo e o quadrado em negrito):

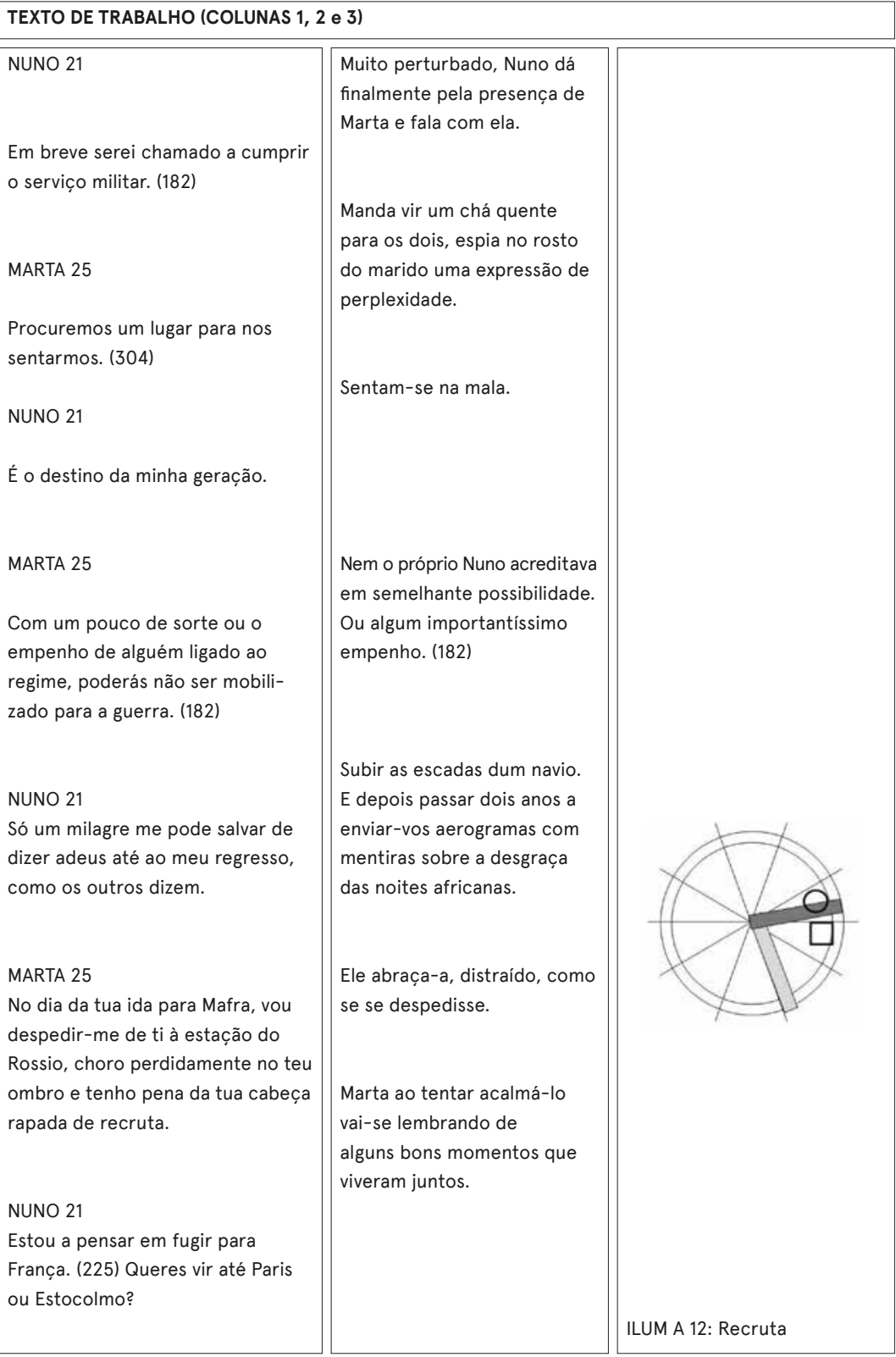


A cenografia, sendo a visualização da dramaturgia, adquire no trabalho de Brites o status de ação visual, pois deve acompanhar o desenvolvimento da ação cênica, a evolução dos conflitos e a intensidade dramática das situações. Por não se resumir ao pano de fundo da ação, a cenografia independente de dispositivos materiais, podendo se restringir a um palco nu onde o corpo e o gesto do ator são os elementos cenográficos que estabelecem relações com aquilo que o rodeia, orientação que recobra os princípios do teatro de Jerzy Grotowski.

Compete ainda à cenografia as relações que serão demarcadas entre o ator e o público, a localização da plateia e o campo de visão que oferece a cada um dos espectadores. A potência visual da cenografia deve atentar-se para a conjugação de elementos binários como perto-longe, claro-escuro, frente-atrás, que se convertem em aspectos de tridimensionalidade. Para o dramaturgo-encenador-cenógrafo João Brites, a cena versa como uma escultura em que a ação visual determina os volumes, sombras, movimentos, alternando-se entre o que dá a ver e o que esconde.

Como artistas, estamos empenhados em tornar visível, mas não no sentido de uma revelação. $O$ jogo de ocultação, sendo fundamental para quem quer criar ambiguidades e despertar consciências, manifesta assim a vontade de partilhar cumplicidades, de indiciar, sugerir e insinuar caminhos num movimento contínuo de interrogação e inquietação. (Brites, 2011a: 22)

Pode perceber-se que a tríade dramaturgia-cenografia-encenação se desenvolve em larga medida pelas mãos de João Brites, salvo os casos em que divide algumas dessas tarefas com outros artistas, como o cenógrafo Rui Francisco. Entretanto, nas duas últimas décadas passou a dedicar-se mais ao trabalho do ator, o qual vem investigando e propondo uma metodologia estruturada ${ }^{2}$ a partir da ideia de ator consciente, inspirada nas proposições do médico, neurocientista (e compatriota) António Damásio. Se o tempo do ator em cena é o tempo presente, o teatro exige que sua performance se mantenha em estado de atualização constante, em que a consciência é a ferramenta decisiva para esse processo. Não se trata de entregar-se à encenação e mergulhar nela, mas de estar consciente de si, de suas ações, gestos, movimentos e também de tudo aquilo que o cerca.

2 Essa metodologia desenvolvida e aprimorada por João Brites no Teatro O Bando e na Escola Superior de Teatro e Cinema (ESTC), onde leccionou uma disciplina de direção de atores para os alunos do último ano da graduação em interpretação, até ao ano lectivo de 2012/13. 
Os espetáculos encenados por João Brites, por seu caráter eminentemente plástico, oferecem ao espectador imagens ambíguas, plurais, que justapõem elementos distintos (corpos, projeções, dispositivos, máquinas de cena, texturas, cores, tons, volumes) que inquietam quem olha, principalmente por corroborarem a construção da ação visual que os põe em movimento e em estado de transformação. São imagens intrigantes porque investem na abstração, e o princípio teatral da transformação promove nelas deslocamentos de sentido, altera a percepção de quem olha, desestabilizando noções como permanência e estabilidade. A composição dos quadros cênico-visuais deste encenador joga com a apreensão e a fruição do público, exigindo um olhar atento, crítico, em busca de respostas. Ao contrário de outros objetos artísticos, como pinturas e esculturas, que permitem um olhar mais demorado pela sua constituição estável, o teatro, dinâmico, ainda conjuga suas imagens com outros elementos verbais e sonoros, construindo uma intrigante rede de sentidos.

A linguagem da representação teatral, para João Brites, está diretamente relacionada com a abstração que se torna um recurso decisivo para instaurar o espaço da ficção. Seu gosto de encenar textos não escritos para o palco, além da liberdade de criação que permitem, está ligado à convicção de que o teatro não se restringe a uma exposição (verbal) de ideias ou conversas, mas à revelação de conteúdos que pode ser dada «através da relação com o espaço, com a corporalidade dos atores, das situações e tensões imagéticas implícitas ou explícitas e de muitas outras formas que ultrapassam o simples conteúdo das palavras que são ditas» (Brites, 2009:271).

Ainda que a dramaturgia de João Brites privilegie a escolha de textos em discurso direto, é nos momentos de maior narratividade (discurso indireto) que o ator deve encontrar seu ouvinte, o espectador, e dirigir-se a ele. Em Jerusalém, há um único momento em que as personagens narram sobre si mesmas na terceira pessoa (autonarração em discurso indireto), no reencontro de Mylia e Ernst: «MYLIA 39 EXPLICA Mylia sorri; a voz transformara-se num corpo,/ ERNST 4O EXPLICA Ernst encontrou-a porque veio por um caminho não material./ MYLIA 39 EXPLICA Mylia pensa: reconheci a tua mão calma» (Brites, 2008: 33). Em outra cena, Mylia e Theodor dirigem-se ao proscênio para justificar ao público a crise do seu relacionamento conjugal. Utilizando-se da alternância entre «falar» (diálogo intersubjetivo) e «explicar» (para o público), a cena comporta-se como uma janela que se abre e fecha ao espectador, transitando entre o dramático e narrativo.

Esses espetáculos desenvolvem uma linguagem própria, autôno-ma, sem impedir o espectador de preservar seu imaginário na leitura: 
"A adaptação de um texto constitui-se apenas como uma versão cênica do que se encontra escrito. A partir do momento em que há uma releitura, eu considero a obra como se fosse minha - por intuição, por paixão, por reformulação, por afeto» (Brites, 2009:271). Ao escrever a partir de outra escrita (romanesca), acrescentando ao texto os elementos da cena, João Brites assume-se autor do espetáculo. Em sua dramaturgia acentua-se o processo de colagem de textos (do mesmo autor ou de autores distintos), experimentando formas de fragmentação e contaminação de materiais e de sentido no próprio decurso do espetáculo, praticando o gesto de cortar e colar, coser e descoser o texto. Ao privilegiar como fonte textual a literatura de língua portuguesa, João Brites e $\mathrm{O}$ Bando permitem-se arriscar no desafio da escolha de textos declaradamente não escritos para o palco, construindo uma fuga dos lugares-comuns da dramaturgia convencional (texto dramático escrito previamente para a cena, unidades de tempo, ação e espaço, divisão ortodoxa ator/personagem, por exemplo) e investindo na possibilidade de elaborar e reelaborar seus espetáculos. 


\section{REFERÊNCIAS BIBLIOGRÁFICAS}

BRITES, João (2002), «Gente Feliz com Lágrimas - texto de trabalho», Palmela, Teatro O Bando (versão de 8 de Outubro de 2002).

- (2004), «Ensaio sobre a Cegueira - texto de trabalho», Palmela, Teatro O Bando (versão de 22 de Novembro de 2004).

- (2008) «Jerusalém - texto de trabalho», Palmela, Teatro O Bando (versão de 4 de Outubro de 2008).

- (2009), «Cenas de leitura e desleitura no teatro d'O Bando-Entrevista com João Brites», Texto e Imagem: Estudos de teatro, Maria Helena Werneck \& Maria João Brilhante (orgs.), Rio de Janeiro, 7 Letras, pp. $265-87$.

- (2011a), «Do outro lado: o que fazemos transcende o que pensamos» [Catálogo], org. Maria Helena Serôdio, Do Outro Lado. Portugal: Quadrienal de Praga 2011. Espaço e Design da Performance, Lisboa, Direcção-Geral das Artes / Ministério da Cultura de Portugal, pp. 11-24.

- (2011b), entrevista concedida a Juarez Guimarães Dias, Palmela, 1 arquivo de áudio em $\mathrm{MP}_{3}$ ( 2 h 2 min).

CASTRO, Sara de (2011), entrevista concedida a Juarez Guimarães Dias, Palmela, 1 arquivo de áudio em MP3 (62 min).

FÉRAL, Josette (2008), «Introduction: Towards a Genetic Study of Performance - Take 2», in Theatre Research International, 33 (3), Cambridge, Cambridge University Press e International Federation for Theatre Research, pp. 223-33.

SARAMAgo, José (1995), Ensaio sobre a Cegueira, Lisboa, Editorial Caminho.

SERÔDIO, Maria Helena (1994), «À flor das palavras: uma retórica teatral da paixão nos trabalhos d'O Bando», Monografia de Um Grupo de Teatro no Seu Vigésimo Aniversário, Lisboa, Grupo de Teatro O Bando, pp. 141-52.

TAVARES, Gonçalo M. (2007), Jerusalém, Lisboa, Editorial Caminho.

TEATRO O BANDO (1980), Manifesto 1, Lisboa.

\section{JUAREZ GUIMARÃES DIAS}

Juarez Guimarães Dias é escritor, diretor teatral e professor do Departamento de Comunicação Social da Universidade Federal de Minas Gerais. Doutor em Artes Cênicas, mestre em Literatura e bacharel em Publicidade e Propaganda, realiza pesquisa sobre narrativas em cena e escreve regularmente no seu blogue Escrita em Progresso. 